\title{
Prevalence, Pattern and Factors Associated with Psychiatric Disorders among Persons Arrested for Violent Crimes in Ife/Modakeke Area, Southwestern Nigeria
}

\author{
Musiliu Adejare Lawal', Samuel Kolawole Mosaku², Bolanle Adeyemi Ola3, \\ Olufemi Morakinyo² \\ ${ }^{1}$ Department of Psychiatry, Federal Medical Centre, Ido-Ekiti, Ekiti State, Nigeria \\ ${ }^{2}$ Department of Mental Health, College of Health Sciences, Obafemi Awolowo University, Ile-Ife, Nigeria \\ ${ }^{3}$ Department of Behavioural Medicine, Faculty of Clinical Sciences, Lagos State University College of Medicine, \\ Lagos, Nigeria \\ Email: ${ }^{*}$ kmosaku@yahoo.co.uk
}

Received 20 September 2014; revised 5 November 2014; accepted 20 November 2014

Copyright (C) 2014 by authors and Scientific Research Publishing Inc.

This work is licensed under the Creative Commons Attribution International License (CC BY).

http://creativecommons.org/licenses/by/4.0/

\section{(c) (i) Open Access}

\section{Abstract}

Background: Association between violence and mental disorders has contributed immensely to the stigma associated with mental illness in the society; because people erroneously see mentally ill individuals as dangerous, they will not want to associate with them. Aims: To assess the prevalence and pattern of psychiatric disorders among a sample of the violent offenders and to examine any relationship between psychiatric disorders and crimes. Method: This was a twophase cross-sectional study in three police stations in Ile-Ife/Modakeke area of Nigeria. In the first phase, we screened 400 consecutive adults arrested for violent crimes using the General Health Questionnaire-30. In the second phase, all 36 persons with probable psychopathology were then interviewed with the Present State Examination to make a definitive diagnosis. Results: The mean age of all the subjects was 29.9 years (SD \pm 7.3 ). The male to female ratio was 11:1. Respondents were mostly single (54\%); most had secondary education or less $(82 \%)$ and about $60 \%$ were currently using psychoactive substances (drugs). About $8.5 \%$ of all the subjects had a diagnosable psychiatric disorder; paranoid schizophrenia was the commonest psychiatric disorder (41.2\%). Mentally ill subjects were three times more likely to commit homicidal offence than non-mentally ill subjects. Conclusion: There exists a significant but weak relationship between mental illness and violent crimes.

\footnotetext{
${ }^{*}$ Corresponding author.
} 
Keywords

\section{Prevalence, Psychiatric, Violent Crimes, Nigeria}

\section{Introduction}

The belief that mental illness is associated with violence is common and cuts across cultures [1]. This is not different in Nigeria; Gureje et al. [2] in a study among the Yorubas of Western Nigeria reported that belief in the association between mental disorders and violence is one of the reasons for the stigma associated with the mentally ill. By providing for the detention/compulsory admission of the mentally ill who are likely to pose a danger to others in the law, the notion that the mentally ill are dangerous is further validated [3].

Generally it is thought that schizophrenia and other psychoses predispose subjects to homicidal behaviour [4] [5]. However, other empirical studies have suggested that violence and mental illnesses are only weakly associated and that apparent relationship may be coincidental [6]. Notwithstanding such suggestion, there are some support in the literature for the assumption that there is a moderate but reliable association between mental disorders and violence [7] [8]. This increased risk of violent behaviour is clearly evident for specific psychiatric diagnoses and symptom constellations. Schizophrenia and other psychoses are associated with violence and violent offending, particularly homicide [9]. There is a positive and significant correlation between schizophrenic syndromes and increased rate of antisocial and violent behaviour [10] [11]; this relationship reportedly has both clinical and social significance [12]. Reports have also confirmed the association between psychoactive substance use and violent behaviour [13] [14]. However, research has also shown that the vast majority of violent people are not mentally ill [15].

Most studies done to assess psychiatric morbidity among criminals in Nigeria were conducted on sentenced criminals who are already in prison, including both violent and non-violent offenders [16]. Though violent crimes have been associated with mental disorders, the prison environment itself may precipitate a psychiatric disorder, thus serving as a confounding factor [17]. This study therefore assessed arrested offenders still in police custody, thus removing the effect of the prison environment as a confounding factor [18].

\section{Method}

The study was conducted in two Local Government Areas (LGAs) of Osun State (Ife Central LGA, and Ife East LGA) in the South-Western part of Nigeria, about $220 \mathrm{~km}$ North-East of Lagos. Ife Central LGA has one police station; a Divisional Headquarters for all the police stations in District Zonal Police Command Area, Ife East LGA has two police stations: a "B" Division, and a "C" Division. These three police stations serve as the first major points of call by complainants reporting cases of violence or other crimes.

Ethical clearance was obtained from the Ethical and Research Committee of Obafemi Awolowo University Teaching Hospital Complex. Permission to conduct the study was also obtained from the Commissioner of Police, State Police Command Headquarters, Osogbo, Osun State. The approval was subsequently relayed to the Divisional Police Officers concerned.

\subsection{Procedure}

All subjects arrested for violent crimes and brought to the three police stations were interviewed consecutively within two days of their arrest, not taking into consideration the final disposal of the case.

Exclusion criteria included: being arrested for non-violent crimes, seriously injured or unconscious suspects and children (these would not be able to give consent or respond appropriately to the questions). Written consent was obtained from all the participants, who agreed to be involved in the study, after a full explanation of the nature and purpose of the study. For those whose lawyers were around, permission was also sought from their lawyers who could sit in during the interview if the client so wish.

The study was a two-phase cross-sectional study. In the first phase all consecutive arrested offenders over the five month (June-November 2012) study period were approached to be included in the study and screened with the General Health Questionnaire (GHQ 30) using either the English or Yoruba version. A total of 474 consecu- 
tive offenders were approached, however 74 refused to participate in the study representing $16 \%$, while 400 agreed to participate, giving a consent rate of $84 \%$. There were no differences between those who refused to give consent and those who agreed to participate in the study in terms of sociodemographic variables.

In the second phase, subjects who scored 5 and above on GHQ-30 and 10\% of those who scored less than 5 on the GHQ (selected at random) were interviewed using the Present State Examination PSE (English or Yoruba translation) to make definitive diagnosis. Syndromes were then derived from symptoms elicited using the Syndrome Checklist (SCL) contained in the PSE manual. An Axis I diagnosis was made in each case if it fulfilled the diagnostic criteria for ICD-10 using the Diagnostic Description and Clinical Guidelines of the ICD-10. In all, 73 persons were interviewed with the Present State Examination.

\subsection{Instruments}

A socio-demographic, clinical and forensic interview schedule was purposely constructed for the study by the authors to elicit information on variables such as; age, sex, educational level, previous history of mental illness, alleged offence, psychoactive substance use etc.

The General Health Questionnaire (GHQ) was devised by David Goldberg [19] as a self-administered screening instrument to aid detection of non-psychotic psychiatric disorder. It can also be used to assess psychiatric morbidity in the community. It helps to identify current psychiatric disturbances, which may then be further classified by a standard interview. The 30 items version was used in this study. A valid Yoruba version [20] has also been developed and has been used in previous studies [21] [22], either the English or Yoruba version was administered, depending on the language understood by the subject. At a cut-off point of 5 , it has a sensitivity of $85.9 \%$ and specificity of $72.9 \%$ [20].

The Present State Examination (PSE), developed by Wing, Sartorius and Cooper [23], is a structured clinical interview designed for adults with neurotic or functional psychotic illness. The presence of a syndrome may be directly rated from interviews, or case notes, using the Syndrome Check List (SCL) which has been included in the manual so that symptoms can be grouped together and diagnosis made. The PSE is used for research purposes as well as for clinical work. It was used in the WHO international pilot study on schizophrenia [24] during which a valid Yoruba version was developed and has been used in many studies since [21] [22].

\subsection{Statistical Analysis}

The Statistical Package for Social Science, Eleventh Version (SPSS 11) was used to process the data. Descriptive statistic was used.

The subjects were divided into groups, based on the presence or absence of psychiatric disorder as well as the nature of the offence committed (homicidal or non-homicidal). The groups were compared using Fishers' Exact Probability Test. Also, Risk Ratio was used to examine the relationship between violent offence and psychiatric disorder. The level of significance was set at less than 0.05 .

\section{Results}

The subjects were predominantly males, 367 (91.7\%). The age range was from 18 to 54 years; but about two thirds of them, 271 (67.8\%), were below 32 years. The mean age was 29.9 years (SD \pm 7.3 ). Other socio-demographic variables of the subjects are shown in Table 1. Assault (simple and aggravated) was the most common complaint against respondents (51.2\%), also 235 (58.8\%) of respondents agreed to currently using psychoactive substances, many of these 131 (55.8) admitting to using multiple substances (alcohol, tobacco, cannabis) while $41.2 \%$ deny the use of any psychoactive substance. Among respondents who agreed to the use of at least one psychoactive substance $74 \%$ had a specific psychiatric diagnosis (Table 2).

Out of all the respondents, 36 (9\%) screened positive (scored 5 or more) for probable psychopathology on the GHQ. However using PSE to interview all 36\% and 10\% of those who screened negative, 34 respondents were diagnosed as having a specific psychiatric disorder giving a prevalence of $8.5 \%$ for psychiatric morbidity among the offenders. Among offenders with specific psychiatric diagnosis, paranoid schizophrenia was the commonest psychiatric disorder (41.2\%), followed by bipolar affective disorder (manic episode) (23.5\%), persistent delusional disorder was next (14.7\%), unspecified psychotic disorder (11.8\%) and schizoaffective disorder (5.9\%), while $2.9 \%$ of the subjects had depressive episode (Table 3 ). Figure 1 shows the distribution of psychopathol- 
Table 1. Socio-demographic variables of all respondents $(n=400)$.

\begin{tabular}{|c|c|c|}
\hline Variable & Frequency & Percentage \\
\hline \multicolumn{3}{|l|}{ Gender } \\
\hline Male & 367 & 91.7 \\
\hline Female & 33 & 8.3 \\
\hline \multicolumn{3}{|l|}{ Age in Years } \\
\hline $18-29$ & 266 & 66.5 \\
\hline $30-44$ & 110 & 17.5 \\
\hline$>45$ & 24 & 6.0 \\
\hline \multicolumn{3}{|l|}{ Marital Status } \\
\hline Single & 216 & 54.0 \\
\hline Married & 148 & 37.0 \\
\hline Separated/Divorced & 36 & 9.0 \\
\hline \multicolumn{3}{|l|}{ Educational Status } \\
\hline No School & 12 & 3.0 \\
\hline Primary Education & 80 & 20.0 \\
\hline Secondary Education & 236 & 59.0 \\
\hline Post Secondary Education & 72 & 18.0 \\
\hline \multicolumn{3}{|l|}{ Occupational Status } \\
\hline I-Professional & 9 & 2.3 \\
\hline II-Intermediate & 4 & 1.0 \\
\hline III—Skilled & 154 & 38.5 \\
\hline IV—Semi Skilled & 77 & 19.2 \\
\hline V-Unskilled & 76 & 19.0 \\
\hline VI-Unemployed & 80 & 20.0 \\
\hline \multicolumn{3}{|l|}{ Employment Status } \\
\hline Self Employed & 201 & 50.3 \\
\hline Employed by Private & 107 & 26.7 \\
\hline Unemployed & 80 & 20.0 \\
\hline Employed by Government & 12 & 3.0 \\
\hline
\end{tabular}

ogy among respondents by their sex.

Table 4 shows the comparison of crimes committed by the subjects with PSE diagnosis with those committed by the subjects without PSE diagnosis. Among the respondents with psychiatric diagnosis, 20.6\% committed homicidal offences compared with $7.9 \%$ of the apparently mentally healthy subjects. This difference was statistically significant $\left(\chi^{2}=4.77, \mathrm{p}=0.023\right)$. Also from Table 4 , risk analysis showed that there is a Risk Ratio of 20.6/7.9 (2.6). This means that the risk of committing a homicidal offence by a mentally ill subject is more than double the risk by an apparently mentally healthy subject.

\section{Discussion}

The relationship between violence and mental disorder has interested scholars (psychiatrists inclusive) for centuries. Particular interest has been attached to mentally ill persons committing very violent crimes, especially 
Table 2. Forensic characteristics of the respondents $(n=400)$.

\begin{tabular}{|c|c|c|}
\hline Variable & Frequency & Percentage \\
\hline \multicolumn{3}{|l|}{ Alleged offence } \\
\hline Simple assault & 205 & 51.2 \\
\hline Aggravated assault & 107 & 26.8 \\
\hline Armed robbery & 36 & 9.0 \\
\hline Murder & 20 & 5.0 \\
\hline Manslaughter & 16 & 4.0 \\
\hline Rape & 16 & 4.0 \\
\hline \multicolumn{3}{|l|}{ Current drug use } \\
\hline Yes & 235 & 58.8 \\
\hline No & 165 & 41.2 \\
\hline \multicolumn{3}{|l|}{ Type of drug use } \\
\hline Multiple* (alcohol, tobacco, cannabis) & 131 & 32.8 \\
\hline Alcohol only & 76 & 19.0 \\
\hline Tobacco & 24 & 6.0 \\
\hline Cannabis & 4 & 10.0 \\
\hline Non & 165 & 41.2 \\
\hline \multicolumn{3}{|l|}{ Previous arrests for crime } \\
\hline Yes & 75 & 18.8 \\
\hline No & 325 & 81.2 \\
\hline \multicolumn{3}{|l|}{ Number of previous arrest(s) } \\
\hline Never & 324 & 81.0 \\
\hline Once & 61 & 15.3 \\
\hline Twice & 8 & 2.0 \\
\hline > Twice & 7 & 1.7 \\
\hline \multicolumn{3}{|l|}{ Nature of (previous) crime } \\
\hline Simple assault & 18 & 24.1 \\
\hline Aggravated assault & 10 & 13.3 \\
\hline Robbery & 4 & 5.3 \\
\hline Rape & 4 & 5.3 \\
\hline Others & 39 & 52.0 \\
\hline
\end{tabular}

"Multiple: 2 or more drugs (i.e. tobacco, cannabis and alcohol).

Table 3. Pattern of psychiatric disorders among the subjects (using PSE).

\begin{tabular}{|c|c|c|c|}
\hline \multirow{3}{*}{ Variable } & \multicolumn{2}{|c|}{ Frequency } & \multirow{3}{*}{ Total } \\
\hline & Male & Female & \\
\hline & No (\%) & No (\%) & \\
\hline Paranoid schizophrenia & $11(78.6)$ & $3(21.4)$ & $14(41.2)$ \\
\hline Manic episode & 7 (87.5) & $1(12.5)$ & $8(23.5)$ \\
\hline Persistent delusional disorder & $5(100.0)$ & $0(0.0)$ & $5(14.7)$ \\
\hline Unspecified psychotic disorder & $4(100.0)$ & $0(0.0)$ & $4(11.8)$ \\
\hline Schizoaffective disorder & $2(100.0)$ & $0(0.0)$ & $2(5.9)$ \\
\hline Depressive episode & $1(100.0)$ & $0(0.0)$ & $1(2.9)$ \\
\hline Total & $30(88.2)$ & $4(11.8)$ & $34(100.0)$ \\
\hline
\end{tabular}




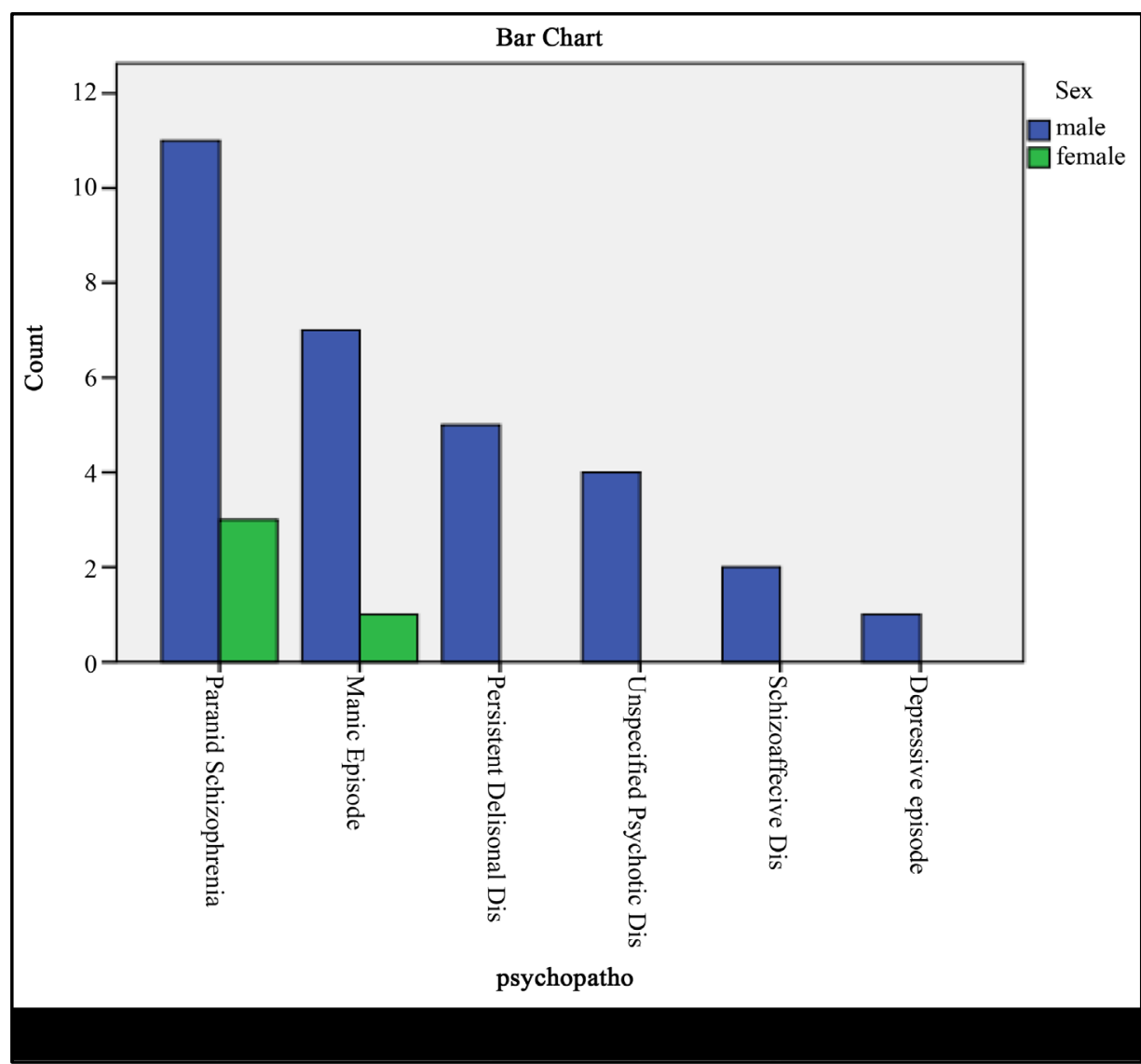

Figure 1. Sex distribution of psychopathology among respondents.

Table 4. Association between type of offence and psychopathology.

\begin{tabular}{ccccc}
\hline \multirow{2}{*}{ Variable } & \multicolumn{2}{c}{ PSE Diagnosis } & Chi Squared Test & Relative Risk \\
\cline { 2 - 3 } & No (\%) & Yes (\%) & & \\
\hline Type of offence & & & & \\
Homicide & $29(7.9)$ & $7(20.6)$ & $\chi^{2}=4.77$ & 2.621 \\
Non-homicide & $337(92.1)$ & $27(79.4)$ & & \\
Total & $366(100.0)$ & $34(100.0)$ & & \\
\hline
\end{tabular}

*Fishers' exact probability test used.

homicide. This has contributed to widespread belief in the society that mentally ill individuals are dangerous, which in turn has contributed to the stigma associated with mental disorders in the society [20] [25]. Nigeria is no exception, Gureje et al. [26] and other researchers have shown that fear of violent behavior by the mentally ill contribute to the stigma associated with mental disorders in the country [27].

Most of the studies on violent behavior and the mentally ill in Nigeria have been among prison inmates [16] [28] however this study is among offenders yet to be convicted, thus the effect of imprisonment and prison condition as a confounder in the occurrence of mental illness was eliminated [18].

The finding in this study that majority of the subjects were young adult males (in their 20s and early 30s) is in keeping with earlier findings both in Nigeria and in other parts of the world [15] [28] [29]. We also found that, males predominate among those arrested for violent crimes, this finding agrees with the notion that violent crime is a predominantly male activity, particularly the younger males [29].

It was observed that assaults, (simple and aggravated) were the predominant violent acts the subjects were al- 
leged to have committed. Abiodun [30] and Ogunlesi et al. [28] reported murder as the predominant crime anomg convicted prisoners. This difference may be explained on the basis of the different setting of these studies, Abiodun [30] and Ogunlesi et al. [28] studied convicted and sentenced offenders, while this study assessed offenders who are basically accused but yet to be convicted or sentenced.

Reports have shown that psychoactive substance use is positively correlated with violent crime [9] [11] [12]. In this study majority (58.8\%) of the subjects admitted to currently using a psychoactive substance and more than half of them currently use a combination of psychoactive substances mainly alcohol and cannabis. This finding attests to the association between violent crime and use of psychoactive substance which has been found in many studies [31] [32].

Among respondents, $8.5 \%$ had diagnosable psychiatric conditions while the rest were basically normal and apparently in good mental health. Compared to studies conducted among prison inmates this prevalence rate is low [16] [18]. The rate is also lower than the $12 \%$ prevalence of mental disorders in the general population in Nigeria reported by Gureje et al. [2], the difference may be due to the instrument used which did identify psychoactive substance use disorder.

Another observation was that, among the mentally ill subjects, the most common diagnosis was schizophrenia (41.2\%). This agrees with finding in other studies [15] [33] [34]. This study showed that the violent offences most likely to be committed by mentally ill offenders, just like apparently mentally healthy offenders, were non-homicidal offences, especially assaults. But, the proportion of the mentally ill subjects that committed homicidal offences was significantly higher than that of the apparently mentally healthy subjects. Most studies that found a relationship between mental illness and violence, found that, that relationship is more likely with serious violent crimes like murder [28] [35].

It was found that the risk of committing a homicidal offence by a mentally ill individual is between two to three times that of an apparently normal individual. This suggests that, truly, an association between mental disorder and violence exists, but this association may not be as strong as it is generally believed in the society. This view was also expressed by Mitchell [36], who after reviewing several studies on the relationship between mental disorder and violent offence, concluded that mental disorders' contribution to violent crime in the community is generally agreed to be small. Similarly Stuart, et al. [15] concluded in their study that people with mental disorders are not major contributors to police identified criminal violence and that public perceptions of mentally ill persons as criminally dangerous appear to be greatly exaggerated.

\section{Limitations}

The study was conducted in two Local Government Areas in South-Western part of Nigeria. Considering the vast nature of this country, it might be difficult to generalise the findings to the entire country. Also the subjects were interviewed within two days of their arrest, thus ascertaining the sincerity with which they answered the questionnaires may be difficult due to their state of mind at the time. Thirdly, an association between mental disorders and violence was established in this study, however, a causal relationship could not be assumed since the study was not controlled. Another limitation is that the main diagnostic questionnaire (PSE) used in this study cannot diagnose psychoactive substance use disorders, mental retardation and personality disorders which may be common among offenders, thus the list of psychiatric diagnosis is not exhaustive.

\section{Conclusion}

Majority of offenders accused of violent crime in this study were found to be mentally healthy and committing non-homicidal offences, especially assaults. Less than $10 \%$ of the violent offenders were mentally ill with majority having paranoid schizophrenia. The mentally ill offenders were more likely to commit homicidal offences, especially murder, compared to the mentally healthy offenders. It appears that there exists a weak relationship between mental disorder and violence with the risk of danger posed by mentally ill persons to the society being relative rather than absolute.

\section{References}

[1] Stuart, H. (2003) Violence and Mental Illness: An Overview. World Psychiatry, 2, 121-124.

[2] Gureje, O., Laosebikan, V.O., Ephraim-Oluwanuga, O., Olley, B.O. and Kola, L. (2005) Community Study of Know- 
ledge of and Attitude to Mental Illness in Nigeria. British Journal of Psychiatry, 186, 436-441.

http://dx.doi.org/10.1192/bjp.186.5.436

[3] Compulsory Admissions and Detention. Mental Health Act 1983.

[4] Junginger, J. and McGuire, L. (2004) Psychotic Motivation and the Paradox of Current Research on Serious Mental Illness and Rates of Violence. Schizophrenia Bulletin, 30, 21-30.

http://dx.doi.org/10.1093/oxfordjournals.schbul.a007064

[5] Richard-Devantoy, S., Olie, J.P. and Gourevitch, R. (2009) Risk of Homicide and Major Mental Disorders: A Critical Review. Encephale, 35, 521-530. http://dx.doi.org/10.1016/j.encep.2008.10.009

[6] Angermeyer, M.C. and Schulze, B. (1998) Mentally Ill Patients-A Danger? Psychiatric Practice, 25, 211-220.

[7] Gunn, J. and Taylor, P.J. (1993) Forensic Psychiatry: Clinical, Legal and Ethical Issues. Butterworth Heinemann, London.

[8] Eronen, M., Angermeyer, M.C. and Schulze, B. (1998) The Psychiatric Epidemiology of Violent Behaviour. Social Psychiatry Psychiatric Epidemiology, 33, S13-S23. http://dx.doi.org/10.1007/s001270050205

[9] Mullen, P.E. (2006) Schizoprenia and Violence: From Correlations to Preventive Strategies. Advances in Psychiatric Treatment, 12, 239-248. http://dx.doi.org/10.1192/apt.12.4.239

[10] Arseneault, L., Moffit, T., Caspi, A., Taylor, P.J. and Silva, P.A. (2000) Mental Disorders and Violence in a Total Birth Cohort. Results from the Dunedin Study. Archives of General Psychiatry, 57, 979-986. http://dx.doi.org/10.1001/archpsyc.57.10.979

[11] Walsh, E., Buchanan, A. and Fahy, T. (2001) Violence and Schizoprenia: Examining the Evidence. British Journal of Psychiatry, 180, 490-495. http://dx.doi.org/10.1192/bjp.180.6.490

[12] Hodgins, S. and Muller-Isberner, R. (2004) Preventing Crime by People with Schizophrenic Disorders: The Role of Psychiatric Services. British Journal of Psychiatry, 185, 245-250. http://dx.doi.org/10.1192/bjp.185.3.245

[13] Fazel, S., Gulati, G., Linsell, L., Geddes, J.R. and Grann, M. (2009) Schizophrenia and Violence: Systematic Review and Meta-Analysis. PLoS Medicine, 6, 100-120. http://dx.doi.org/10.1371/journal.pmed.1000120

[14] Elbogen, E.B. and Johnson, S.C. (2009) The Intricate Link between Violence and Mental Disorder: Results from the National Epidemiologic Survey on Alcohol and Related Conditions. Archives of General Psychiatry, 66, 152-161. http://dx.doi.org/10.1001/archgenpsychiatry.2008.537

[15] Stuart, H.L. and Arboleda-Florez, J.E. (2001) A Public Health Perspective on Violent Offences among Persons with Mental Illness. Psychiatric Services, 52, 654-659. http://dx.doi.org/10.1176/appi.ps.52.5.654

[16] Agbahowe, S., Ohaeri, J., Ogunlesi, A. and Osahon, R. (1998) Prevalence of Psychiatric Morbidity among Convicted Inmates in a Nigeria Prison Community. East African Medical Journal, 75, 19-26.

[17] Gunn, J., Maden, A. and Swinton, M. (1991) Mentally Disordered Prisoners. Home Office, London.

[18] Fazel, S. and Danesh, J. (2002) Serious Mental Disorder in 23,000 Prisoners: A Systematic Review of 62 Surveys. The Lancet, 359, 545-550. http://dx.doi.org/10.1016/S0140-6736(02)07740-1

[19] Goldberg, D. (1972) The Detection of Psychiatric Illness by Questionnaire. Oxford University Press, London.

[20] Abiodun, O.A., Adetoro, O.O. and Ogunbode, O.O. (1993) Psychiatric Morbidity in a Pregnant Population in Nigeria. General Hospital Psychiatry, 15, 125-128. http://dx.doi.org/10.1016/0163-8343(93)90109-2

[21] Aghanwa, H.S. and Erhabor, G.E. (1998) Demographic and Socioeconomic Factors in Mental Disorders Associated with Tuberculosis in Southwest Nigeria. Journal of Psychosomatic Research, 45, 353-360. http://dx.doi.org/10.1016/S0022-3999(98)00006-3

[22] Mosaku, S.K., Erhabor, G.E. and Morakinyo, O. (2007) Specific Psychiatric Morbidity among a Sample of Asthmatics in South Western Nigeria. International Journal of Psychiatry in Medicine, 37, 151-161. http://dx.doi.org/10.2190/9T87-6781-7M3W-04Q4

[23] Wing, J.K., Cooper, J.E. and Sartorius, N. (1974) Measurement and Classification of Psychiatric Symptoms. Cambridge University Press, London.

[24] World Health Organization (1973) Report of the International Pilot Study of Schizophrenia, 1. World Health Organization, Geneva.

[25] Thorton, J.A. and Wahl, O.F. (1996) Impact of a Newspaper Article on Attitudes toward Mental Illness. Journal of Community Psychology, 24, 17-25. http://dx.doi.org/10.1002/(SICI)1520-6629(199601)24:1<17::AID-JCOP2>3.0.CO;2-0

[26] Gureje, O. (2007) Psychiatry in Africa: The Myth, the Exotic and the Realities. South African Psychiatry Review, 10, 11-14.

[27] Adewuya, A.O. and Makanjuola, R.O.A. (2005) Social Distance towards People with Mental Illness amongst Nigerian 
University Students. Journal of Social Psychiatry and Psychiatric Epidemiology, 40, 865-868. http://dx.doi.org/10.1007/s00127-005-0965-3

[28] Ogunlesi, A.O., Makanjuola, J.D.A. and Adelekan, M.L. (1988) Offenders Admitted to the Neuro-Psychiatric Hospital Aro, Abeokuta: A Ten-Year Review. West African Journal of Medicine, 7, 129-135.

[29] Udofia, O. (1997) Mental Illness and Crime in South Eastern Nigeria. Nigerian Journal of Psychiatry, 1, 209.

[30] Abiodun, O. (1986) A Study of Mentally Ill Offenders in a Nigerian Prison Psychiatric Unit. Unpublished Thesis, The National Postgraduate Medical College of Nigeria.

[31] Adesanya, A., Ohaeri, J.U., Ogunlesi, A.O., Adamson, T.A. and Odejide, O.A. (1997) Psychoactive Substance Abuse Among Inmates of a Nigerian Prison Population. Drug and Alcohol Dependence, 47, 39-44. http://dx.doi.org/10.1016/S0376-8716(97)00067-7

[32] McNiel, D.E., Binder, R.L. and Robinson, J.C. (2005) Incarceration Associated with Homelessness, Mental Disorder, and Co-Occurring Substance Abuse. Psychiatric Services, 56, 840-846. http://dx.doi.org/10.1176/appi.ps.56.7.840

[33] Brennan, P.A., Mednick, S.A. and Hodgins, S. (2000) Major Mental Disorders and Criminal Violence in a Danish Birth Cohort. Archives of General Psychiatry, 57, 494-500. http://dx.doi.org/10.1001/archpsyc.57.5.494

[34] Fazel, S. and Grann, M. (2004) Psychiatric Morbidity among Homicide Offenders: A Swedish Population Study. American Journal of Psychiatry, 161, 2129-2131.

[35] Monahan, J., Steadman, H.J., Silver, E., et al. (2001) Risk Assessment: the MacArthur Study of Mental Disorder and Violence. Oxford University Press, Oxford.

[36] Mitchell, E.W. (1999) Does Psychiatric Disorder Affect the Likelihood of Violent Offending? A Review and Critique of the Major Findings. Medicine, Science and the Law, 39, 23-30. 
Scientific Research Publishing (SCIRP) is one of the largest Open Access journal publishers. It is currently publishing more than 200 open access, online, peer-reviewed journals covering a wide range of academic disciplines. SCIRP serves the worldwide academic communities and contributes to the progress and application of science with its publication.

Other selected journals from SCIRP are listed as below. Submit your manuscript to us via either submit@scirp.org or Online Submission Portal.
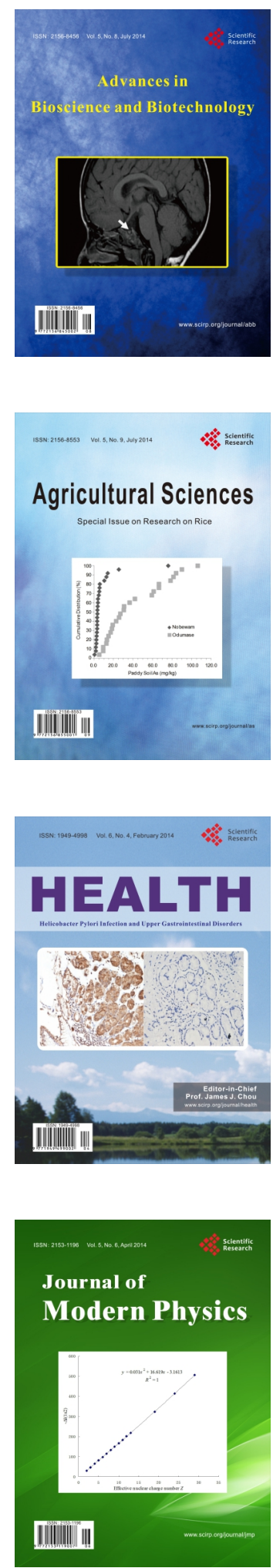
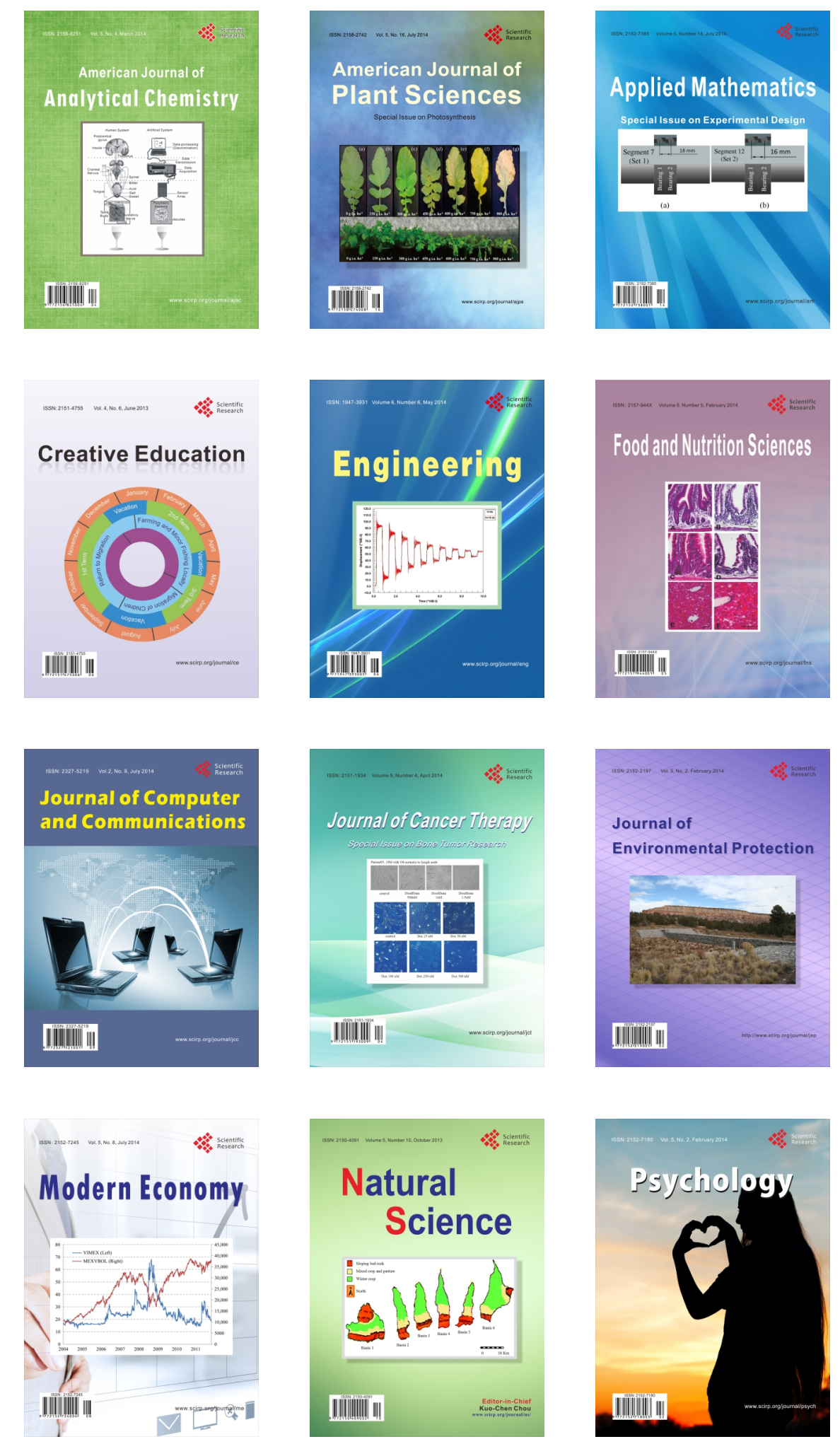